\title{
Association of the maternal experience and changes in adiposity measured by BMI, waist:hip ratio and percentage body fat in urban Brazilian women
}

\author{
Maria L. C. F. Rodrigues ${ }^{1,2}$ and Teresa H. M. Da Costa ${ }^{1}$ * \\ ${ }^{1}$ Department of Nutrition, Faculty of Health Sciences, Universidade de Brasilia, Brasilia, CP 04511, CEP 70919-970, Brazil \\ ${ }^{2}$ Amazon Research Institute, INPA, Manaus, Amazonas, Brazil
}

(Received 8 December 1999 - Revised 6 July 2000 - Accepted 28 July 2000)

\begin{abstract}
The aim of the present study was to determine the association between the maternal experience and changes in adiposity measured by BMI, percentage body fat (PBF) and waist:hip ratio (WHR). In a cross-sectional study, 203 women were recruited at health care and educational facilities in Brasilia, Brazil. These women were divided into three groups: fifty-three nulliparous (no full-term pregnancy); sixty-three primiparous (one full-term pregnancy); eighty-seven multiparous (two or more full-term pregnancies). Socio-economic, behavioural, reproductive and dietary data were collected. All the women were measured for weight, height, skinfold thicknesses and waist and hip circumferences. Analysis of covariance was used to measure the differences among the three groups in relation to BMI, PBF and WHR, controlling for the following covariates: age; socio-economic status; use of oral contraceptives; smoking; energy intake level; cooking oil intake; physical activity level; lactation score; parity. The three groups of women differed significantly for BMI $(P=0.04)$, PBF $(P=0.0008)$ and WHR $(P=$ $0 \cdot 0001)$. Multiparous women presented higher BMI $(P=0.01)$ and PBF $(P=0.03)$ compared with primi- and nulliparous groups. PBF was also associated with age and high socio-economic status. Primi- and multiparous women showed a higher WHR than nulliparous women $(P<$ 0.0001). Age and smoking habit were also factors associated with higher WHR.
\end{abstract}

Pregnancy: Adiposity: BMI: Waist:hip ratio

Maternal obesity is not a new condition (Sheldon, 1949) and medical literature has recorded that women often refer to pregnancy as the main cause of their obesity (Mullins, 1960; Bradley, 1985; Lean et al. 1989; Öhlin \& Rössner, 1990). However, a cause-and-effect relationship between the maternal experience and weight gain has proved difficult to establish due to a large number of possible confounding factors. During the present decade more attention has been paid to this period of physiological fat accretion (Öhlin \& Rössner, 1990, 1994, 1996; Smith et al. 1994; Ness, 1995; Rössner \& Öhlin, 1995; Sohlström \& Forsum, 1995; Björkelund et al. 1996; Harris et al. $1997 a, b$; Wolfe et al. 1997), and some evidence indicates that the maternal experience may be a critical period for the establishment of weight gain and obesity in young women (Harris \& Ellison, 1997).

Weight gain and central distribution of adiposity are related to increased health risks of dislipidaemia, noninsulin-dependent diabetes mellitus, hypertension and CHD
(Lapidus et al. 1984; Manson et al. 1990, 1993; Huang et al. 1998; Martins et al. 1998). Identification of groups of individuals susceptible to weight gain is important for public health intervention, since this group is more prone to obesity and associated comorbidities (Garrow, 1981).

Brazil has been through a nutrition transition, with profound modifications of lifestyle and dietary habits associated with urbanisation (Monteiro et al. 1995). Since 1989 there has been a dramatic shift towards weight gain especially among poor Brazilian women (Monteiro et al. 1995). Results from the Brazilian III Demographic and Health Survey conducted in 1996 showed that obesity in women is now an important issue, as $25.2 \%$ of women of reproductive age (15-49 years) are overweight (BMI $\geq 25 \mathrm{~kg} / \mathrm{m}^{2}$ ) and $9.3 \%$ are obese $\left(\right.$ BMI $\geq 30 \mathrm{~kg} / \mathrm{m}^{2}$; Coitinho, 1998). There is still very limited information available concerning the factors contributing to the high prevalence of obesity in women in Brazil. Our objective was to determine the association between the maternal

\footnotetext{
Abbreviations: EI, energy intake; PBF, percentage body fat; TEE, total energy expenditure; WHR, waist : hip ratio.

* Corresponding author: Dr Teresa Da Costa, fax +55 61349 6286, email hdacosta@unb.br
} 
experience (gestation and lactation) and changes in adiposity measured by BMI, percentage body fat (PBF) and waist : hip ratio (WHR) in a sample of urban Brazilian women, controlling behavioural and demographic factors. Part of this work has already been briefly reported (Da Costa \& Rodrigues, 2000).

\section{Material and methods}

\section{Subjects}

Women included in the present study were healthy nonpregnant, between 18 and 43 years of age and reported no clinical or behavioural conditions such as diabetes mellitus, hypertension, cancer, twin births, in treatment for obesity or broad fluctuations in food intake. Participation of human subjects in the present study was approved by the Ethical Committee of the Faculty of Health Sciences, University of Brasilia. After presentation of the study objectives and formal consent from the volunteers, the protocol was followed, or another close date was organised for the interview and anthropometric measurements. All women who had completed a pregnancy were examined at 12-15 months post-partum. The women ( $n$ 203) were recruited and divided according to parity into three groups: eightyseven multiparous women with two or more complete pregnancies (38-42 weeks gestation); sixty-three primiparous women with one complete pregnancy; fifty-three nulliparous women with no history of complete pregnancy.

\section{Recruitment sites}

The study was conducted in Brasilia, a modern and planned city, where residents have higher incomes. The city is surrounded by small satellite cities. The population in the satellite cities are predominantly of low income and work in Brasilia, using its education and health services. Brasilia has only one public university and one university hospital, both of which receive a large proportion of the population from the surrounding area in search of quality health and education services. Primi- and multiparous women were recruited at the outpatient paediatric clinic during the follow-up consultation for their child at the university hospital, and of a nearby public health centre of the local health authority. Nulliparous women were recruited at two public education centres and at the University of Brasilia. These recruitment sites were chosen because they were close to the University of Brasilia. Recruitment also included personnel who work or study at the University of Brasilia or the university hospital and live in the city of Brasilia, in order to have a more representative sample of the population of Brasilia. Volunteers were accepted for participation in the study according to their order of arrival at these sites. The sample was not biased, as we followed the order of arrival and the weekdays on which data were collected were randomised throughout the period of collection. Care was taken to finalise the three groups with women of the same age range and socio-economic status. Recruitment extended from April 1996 to April 1998. A 6-month pilot study was carried out in October 1995.

\section{Study design and methods}

A cross-sectional study design was adopted to investigate the association between reproductive history and changes in adiposity. Standardised questionnaires were developed to obtain detailed socio-demographic, behavioural, reproductive and dietary information.

Demographic data. The first part of the questionnaire asked for information on the date of birth, address, race, marital status, education, profession and occupation of the woman, and for women who had completed a pregnancy, the profession, present occupation and years of education of the father of the child. Each woman was asked to indicate the range of family income, which was divided into five levels, based on the national minimal wage $(\mathrm{R} \$ 151.00$ or US\$ 83.80). Information on the number of children, with respective ages, and the number of adults living in the household was also obtained. Classification of women into either low or high socio-economic level was based on the information obtained about the family income (with a cutoff point at five times the national minimum wage), in association with a careful analysis of all other demographic information and the presence of commodity goods in the household such as refrigerator and/or freezer.

In a partial report of the present study (Da Costa \& Rodrigues, 2000), marital status was considered in the analysis of covariance (see later, p. 112), but as it did not reach statistical significance, it was removed from the final analysis.

Health and reproductive history. The second part of the questionnaire requested information about the woman's health and reproductive history. Women were asked about any known pathologies, use of drugs or medical prescriptions, use of oral contraceptive, vitamin supplements and smoking. Physical activity was classified into four levels according to programmed physical exercise and occupational activities: (1) sedentary; (2) regular physical exercise $<4$ h/week; (3) regular physical exercise $>4$ h/week; (4) heavy physical activity or competitive sport (Heitmann et al. 1995). Questions about reproductive history included the number of full pregnancies and/or abortions, date of birth, gender and duration of lactation (months) for each child. From the data on duration of lactation, a simple scoring system was established (adapted from the work of Öhlin \& Rössner, 1990), assigning the following number of points per month for each month of breast-feeding: $<1$ month, 0 1-5 months 2, 6 months 3, 7-8 months 4, 9-11 months $5, \geq 12$ months 6 . A range of $0-72$ points could therefore be obtained by each mother per child. The mean lactation score was then calculated by taking the total number of points obtained divided by the number of children. The mean lactation score was used in the analysis as a rough estimate of the total energy expenditure for milk production.

Dietary information. The third part of the questionnaire consisted of dietary information. Two sets of questionnaires were developed to record food intake by $24 \mathrm{~h}$ recall and by food frequency. The food-frequency questionnaire was adapted from that used for the study reported by Sichieri \& Everhart (1998) for the Brazilian population. Food items included in the list represented major contributors to energy 
intake as carbohydrates, fats and beverages. Frequency of consumption was recorded by d, week or month as well as 'never' and 'almost never'. Data on food intake were obtained by the authors or by trained undergraduate students of nutrition who participated in the project. All $24 \mathrm{~h}$ recall and food-frequency questionnaires were closely supervised by one of the authors (mainly M.L.C.F.R.). A combination of dietary assessment methods has been shown to assure better accuracy of dietary information for young women (Sawaya et al. 1996).

At the end of the $24 \mathrm{~h}$ recall questionnaire we included a question designed to indicate whether the data represented habitual intake or whether it represented an atypical intake (i.e. a weekend or party day). To estimate the amount of cooking oil used during the preparation of meals we obtained information on the amount of oil consumed per month and the number of members of the family or household eating the meals. Children $\leq 10$ years of age were considered to have half the intake of an adult. The individual daily oil intake was expressed as $\mathrm{ml} /$ person per $\mathrm{d}$.

Energy intake (EI) was calculated by computer using the Sistema de Apoio à Nutriçâo program version 2.5 (Centro de Informàtica de Saude, Sao Paulo, Brazil). Additional energy values for foods not represented were obtained from the manufacture's food labels or from recipes. We obtained the weight $(\mathrm{g})$ of total carbohydrate, protein and fat in the diet and calculated the energy value by multiplying by $16.7 \mathrm{~kJ}(4 \mathrm{kcal}) / \mathrm{g}, 16.7 \mathrm{~kJ}(4 \mathrm{kcal}) / \mathrm{g}$ and $37.7 \mathrm{~kJ}(9 \mathrm{kcal}) / \mathrm{g}$ respectively. Total energy was calculated as the sum of the three values.

We divided the EI into categories from the estimation of total energy expenditure (TEE). The equations of the Food and Agriculture Organization/World Health Organization/ United Nations University (1985) based on gender, age and body weight were used to estimate BMR. To correct for the presence of under- or overweight individuals in the sample, we considered the ideal body weight of each women as height $(\mathrm{m})^{2} \times 22$ (Keys et al. 1972). TEE was calculated by multiplying BMR by the average daily physical activity level (1.56, 1.64 and 1.82 for sedentary, moderate or heavy physical activity respectively). A further $2 \cdot 1 \mathrm{MJ}$ (500 kcal)/d Food and Agriculture Organization/World Health Organization/United Nations University (1985) was added to the TEE for all women who were breastfeeding. Mean TEE was 9.40 (SD 1.1) MJ (2246 (SD 257) $\mathrm{kcal}) / \mathrm{d}$ for the whole sample. The cut-off values were calculated as mean and $1 \mathrm{SD}$. The levels of EI (MJ) were then established as: 1 , $\leq 8 \cdot 2,2,8 \cdot 3-9 \cdot 3,3,9 \cdot 4-10 \cdot 4,4$, $\geq 10 \cdot 5$. Women were first classified into one of the four levels of EI according to the value for EI calculated from the $24 \mathrm{~h}$ recall, and then classified according to the frequency of intake of the energy-rich food items. The two sets of information were combined and the level of EI adjusted to give a final level of EI for each woman. The dietary data analysis and the adjustment of the EI level were performed blindly for parity, and revised independently by the two authors. This procedure allowed us to use a one-parameter statistical model which took into consideration the quantitative $(24 \mathrm{~h}$ recall) and qualitative (food frequency) dietary information.

\section{Anthropometry}

Anthropometric measurements were performed in all women wearing light clothing and without shoes. For weight and height the procedure described by Jelliffe (1966) was followed. The weight measurements were performed on the same set of digital scales. All scales were periodically checked for precision (Soehnle 7306; Soehnle, Germany and Filizola, São Paulo, Brazil). Weight was measured to the nearest $0 \cdot 1 \mathrm{~kg}$. Height was obtained using a Microtoise tape (Stanley, London, UK) to the nearest $0.1 \mathrm{~cm}$. BMI was calculated as weight divided by height ${ }^{2}$ $\left(\mathrm{kg} / \mathrm{m}^{2}\right)$. For the purpose of the present study we adopted the World Health Organization (1998) classification of body weight in adults according to BMI $\left(\mathrm{kg} / \mathrm{m}^{2}\right)$ : normal weight 18.5-24.9; overweight 25.0-29.9; obese $\geq 30 \cdot 0$.

We chose not to obtain pre-pregnant weight through recall as it would have been more difficult to rely on the information, especially for multiparous women for whom the period of recall would be greater. It was impossible to obtain medical records of weight before pregnancy for the sample studied.

Skinfold measurements were performed on the right side of the body at the following sites: triceps; subscapular; suprailiac, thigh. Thus, two measurements were obtained for both the upper and lower body. Measurements were taken to the nearest $0.2 \mathrm{~mm}$ with a Harpender calliper (CMS Weighing Equipment, London, UK) and the average of the two readings recorded. A third reading was taken if a difference of more than $1 \mathrm{~mm}$ was obtained and the two closest readings were averaged. The equations of Durnin \& Womersley (1974) were used to estimate body density and the equation of Siri (1961) was used to calculate PBF.

Waist circumference was measured midway between the lowest rib margin and the iliac crest, where the smallest measurement was obtained using a tape measure. Hip circumference was measured at the widest point between the iliac crest and buttock. All circumferences and skinfold thicknesses were measured with the subject standing. WHR was calculated as waist circumference divided by hip circumference.

All anthropometric measurements were performed independently by the authors. Measurements were shared evenly between the two anthropometrists among the parity groups, and data collection was performed according to a pre-established schedule. Intra- and inter-observer evaluation was conducted in a subset of subjects ( $n$ 21). In this sample measurements were randomized by the observers. High inter-observer correlation was found in relation to skinfold $(r>0.95, P<0.0001)$ and circumference $(r=$ $0.99, P<0.0001)$ measurements. There were no statistical differences with respect to intra-observer measurements.

\section{Statistics}

Analysis of covariance was used to evaluate mean differences in adiposity measured by BMI, PBF and WHR among the three groups. Maternal age, socioeconomic status, oral contraceptive use, smoking, lactation score, physical activity level, EI level, cooking oil intake and parity were included as covariates in the model. 
Table 1. Demographic, behavioural, dietary and anthropometric characteristics of nulli-, primi- and multiparous urban Brazilian women* (Mean values with their standard errors; other values represent the no. of subjects in each category)

\begin{tabular}{|c|c|c|c|c|c|c|}
\hline \multirow[b]{2}{*}{ Variables } & \multicolumn{2}{|c|}{ Nulliparous ( $n$ 53) } & \multicolumn{2}{|c|}{ Primiparous ( $n$ 63) } & \multicolumn{2}{|c|}{ Multiparous ( $n$ 87) } \\
\hline & Mean & SE & Mean & SE & Mean & SE \\
\hline \multicolumn{7}{|l|}{ Demographic } \\
\hline Age (years) & $25 \cdot 4$ & $4 \cdot 8$ & $25 \cdot 4$ & $5 \cdot 0$ & $28 \cdot 3$ & $5 \cdot 5$ \\
\hline Socio-economic status: High & & & & & & \\
\hline Low & & & & & & \\
\hline \multicolumn{7}{|l|}{ Behavioural } \\
\hline Physical activity level: $L$ & & & & & & \\
\hline$M$ & & & & & & \\
\hline 1 & & & & & & \\
\hline Lactation score (points) & & & $43 \cdot 6$ & $3 \cdot 8$ & $45 \cdot 4$ & $2 \cdot 2$ \\
\hline Oral contraceptive use: Yes & & & & & & \\
\hline No & & & & & & \\
\hline Smoking: Yes & & & & & & \\
\hline No & & & & & & \\
\hline \multicolumn{7}{|l|}{ Dietary } \\
\hline Energy intake level†: 1 & & & & & & \\
\hline 2 & & & & & & \\
\hline 3 & & & & & & \\
\hline 4 & & & & & & \\
\hline Cooking oil intake (ml) & $17 \cdot 4$ & $9 \cdot 3$ & 24.9 & $14 \cdot 2$ & $26 \cdot 0$ & $14 \cdot 0$ \\
\hline Energy intake (MJ) & $6 \cdot 6$ & $2 \cdot 2$ & $8 \cdot 2$ & $2 \cdot 8$ & 7.4 & 2.9 \\
\hline Protein (\% total energy) & 15 & 3.4 & 14 & 4.0 & 14 & 4.8 \\
\hline Fat (\% total energy) & 38 & $8 \cdot 1$ & 36 & $9 \cdot 3$ & 36 & $8 \cdot 1$ \\
\hline Carbohydrate (\% total energy) & 47 & $9 \cdot 3$ & 51 & $11 \cdot 2$ & 50 & $10 \cdot 6$ \\
\hline \multicolumn{7}{|l|}{ Anthropometric } \\
\hline Body weight (kg) & $54 \cdot 7$ & $8 \cdot 3$ & 54.8 & 8.9 & $57 \cdot 8$ & $9 \cdot 8$ \\
\hline Height (m) & 1.58 & 0.07 & 1.57 & 0.06 & 1.57 & 0.06 \\
\hline BMI $\left(\mathrm{kg} / \mathrm{m}^{2}\right)$ & $21 \cdot 8$ & 2.9 & $22 \cdot 1$ & $3 \cdot 7$ & $23 \cdot 6$ & $3 \cdot 6$ \\
\hline Total body fat (\%) & $27 \cdot 2$ & 4.6 & $26 \cdot 0$ & $5 \cdot 6$ & $28 \cdot 2$ & 5.5 \\
\hline Waist circumference $(\mathrm{cm})$ & $69 \cdot 0$ & $6 \cdot 4$ & $73 \cdot 7$ & $8 \cdot 1$ & $76 \cdot 6$ & $8 \cdot 1$ \\
\hline Hip circumference $(\mathrm{cm})$ & 93.0 & $14 \cdot 0$ & $92 \cdot 7$ & $7 \cdot 1$ & 95.5 & $7 \cdot 7$ \\
\hline WHR & 0.73 & 0.05 & 0.79 & 0.05 & 0.80 & 0.05 \\
\hline
\end{tabular}

L, light; M, moderate; I, intense; WHR, waist: hip ratio.

* For details of procedures, see p. 108.

† Energy intake level (MJ): $1 \leq 8 \cdot 2,2$ 8.3-9.3, 3 9.4-10.4, $4 \geq 10 \cdot 5$; for details of classification, see p. 109.

Statistical analysis was performed using Statistical Analysis Systems software package version 6.04 (SAS Institute Inc., Cary, NS, USA). $P<0.05$ was considered to be significant.

\section{Results}

Demographic, behavioural, dietary and anthropometric characteristics of the three groups are presented in Table 1. Women enrolled in the present study were mostly young, with $66 \%$ of the sample being between 19 and 28 years of age. They were mainly low socio-economic status $(>60 \%)$, were non-smoking $(>75 \%)$ and had a sedentary physical activity level $(>70 \%)$. Very few women in the primi- and multiparous groups reported a moderate or intense physical activity level. Some nulliparous women reported being more active with $11.3 \%$ and $17 \%$ of the nulliparous sample reporting moderate or intense physical activity respectively. Use of oral contraceptive pills was more frequent among primiparous women (55\%), while the majority of nulli- (77\%) and multi- $(66 \%)$ parous women did not use this method of contraception.

On average women had a BMI within the normal range (Table 1) but with a tendency to a higher BMI with increasing parity. PBF was $\leq 28.2 \%$ in all groups. Primiand multiparous women showed a larger waist circumfer- ence and consequently a greater WHR. EI levels 1 $(\leq 8.2 \mathrm{MJ})$ and $2(8.3-9.3 \mathrm{MJ})$ were predominate in all groups (\%): nulliparous 85 ; primiparous 67 ; multiparous 70. Intake of cooking oil was about $70 \%$ higher for primiand multiparous women than for the nulliparous group. Nulliparous women had the lowest average EI and the percentage of dietary energy from the different macronutrients were typical of a Western diet; higher in fat $>35 \%$ total EI) and proportionally lower in carbohydrates $(<55 \%$ total EI). The majority of the women examined were from a lower-income urban population.

Analysis of covariance controlling for the covariates presented in Table 2 shows that the three groups of women differed significantly for BMI $(P=0 \cdot 04)$, PBF $(P=$ $0.0008)$ and WHR $(P=0.0001$; full model $)$. There were significant increases in BMI $(P=0.01)$ and $\operatorname{PBF}(P=$ $0 \cdot 03$ ) with multiparity (Table 3 ) and an inverse association between BMI and PBF and EI level $(P=0 \cdot 02)$. PBF was significantly higher for women with a higher socioeconomic status $(P=0.02$; Table 3$)$ and was significantly associated with age $(P=0 \cdot 007$; Table 2$)$.

Primi- and multiparous had significantly higher WHR $(P=0.0001)$, which was associated in the model with age $(P=0.03)$ and smoking $(P=0.01)$. There was a borderline statistical significant $(P=0.06)$ association with socio-economic status (Table 2). Primi- and multiparous 
Table 2. Analysis of covariance for body mass index (BMI), percentage body fat (PBF) and waist: hip ratio (WHR) in urban Brazilian women

\begin{tabular}{|c|c|c|c|c|c|c|}
\hline \multirow[b]{2}{*}{ Model } & \multicolumn{2}{|c|}{ BMI } & \multicolumn{2}{|c|}{ PBF } & \multicolumn{2}{|c|}{ WHR } \\
\hline & $\mathrm{F}$ & $P$ & $\mathrm{~F}$ & $P$ & $\mathrm{~F}$ & $P$ \\
\hline Full model & 1.85 & $0.04^{*}$ & 2.90 & $0.0008^{*}$ & 8.86 & $0.0001^{\star}$ \\
\hline Age & 0.13 & 0.71 & $7 \cdot 27$ & $0.007^{\star}$ & 5.03 & $0.03^{*}$ \\
\hline Socio-economic status & 0.91 & 0.34 & $5 \cdot 23$ & $0.02^{*}$ & 3.65 & 0.06 \\
\hline Oral contraceptive agent & $0 \cdot 10$ & 0.76 & 0.03 & 0.87 & 1.47 & 0.23 \\
\hline Smoking & 1.59 & 0.21 & 1.51 & 0.22 & $6 \cdot 35$ & $0.01^{*}$ \\
\hline Energy intake level & $2 \cdot 86$ & $0.04^{*}$ & 2.72 & $0.04^{*}$ & 0.87 & 0.46 \\
\hline Cooking oil intake & 0.05 & 0.83 & 0.07 & 0.79 & 0.33 & 0.56 \\
\hline Physical activity level & 0.12 & 0.88 & 1.42 & 0.24 & 1.03 & 0.36 \\
\hline Lactation score & 0.97 & 0.33 & 1.49 & 0.22 & 0.26 & 0.61 \\
\hline Parity & 6.34 & $0.002^{*}$ & 3.55 & $0.03^{*}$ & $16 \cdot 09$ & $0.0001^{\star}$ \\
\hline$R^{2}$ & \multicolumn{2}{|c|}{0.11} & \multicolumn{2}{|c|}{0.17} & \multicolumn{2}{|c|}{0.38} \\
\hline
\end{tabular}

${ }^{*} P$ values which reached significance.

women had significantly higher WHR than nulliparous women $(P=0 \cdot 0001$; Table 3$)$. Smoking was associated with a higher WHR (0.80) compared with non-smoking women $(0 \cdot 77, P=0 \cdot 01$; Table 3$)$.

\section{Discussion}

The present work has shown a significant association between changes in body mass and body fat distribution in a sample of urban Brazilian women after the maternal experience. The present study shows for the first time, in Brazilian women, that an increase in parity is related to central fat distribution after adjustment of the covariates known to influence an increase and distribution of body fat.

There are some methodological limitations in a study with a cross-sectional design. These include systematic biases associated with recall of dietary intake, environmental and behavioural data. There might also be intrinsic

Table 3. Comparison by least square means of body mass index $(\mathrm{BMI})$, percentage body fat (PBF) and waist:hip ratio (WHR) according to parity, socio-economic status, smoking status, and energy intake level in urban Brazilian women*

\begin{tabular}{|c|c|c|c|}
\hline & BMI & PBF & WHR \\
\hline Covariates & Mean & Mean & Mean \\
\hline \multicolumn{4}{|l|}{ Parity } \\
\hline Nulliparous & $20 \cdot 5^{\mathrm{a}}$ & $26 \cdot 3^{\mathrm{e}}$ & $0.74^{\mathrm{g}}$ \\
\hline Primiparous & $22 \cdot 0^{a}$ & $27 \cdot 2^{e}$ & $0.81^{h}$ \\
\hline Multiparous & $23 \cdot 4^{b}$ & $29 \cdot 1^{f}$ & $0.81^{\mathrm{h}}$ \\
\hline \multicolumn{4}{|c|}{ Socio-economic status } \\
\hline Low & $21 \cdot 7$ & $26 \cdot 6^{c}$ & 0.79 \\
\hline High & $22 \cdot 2$ & $28 \cdot 5^{d}$ & 0.78 \\
\hline \multicolumn{4}{|l|}{ Smoking } \\
\hline No & $22 \cdot 4$ & $28 \cdot 2$ & $0.77^{\mathrm{a}}$ \\
\hline Yes & 21.5 & $27 \cdot 0$ & $0 \cdot 80^{\mathrm{b}}$ \\
\hline \multicolumn{4}{|c|}{ Energy intake level (MJ) } \\
\hline $1(\leq 8 \cdot 2)$ & $23.0^{c}$ & $29 \cdot 0^{\mathrm{c}}$ & 0.79 \\
\hline $2(8 \cdot 3-9 \cdot 3)$ & $22 \cdot 6^{\mathrm{C}}$ & $28 \cdot 6^{c}$ & 0.79 \\
\hline $3(9.4-10.4)$ & $20 \cdot 7^{d}$ & $26 \cdot 0^{d}$ & 0.78 \\
\hline $4(\geq 10.5)$ & $21 \cdot 5^{\mathrm{d}}$ & $26 \cdot 7^{d}$ & 0.77 \\
\hline
\end{tabular}

a,b,c,d,e,f,g,h Mean values within a column and covariate category with unlike superscript letters were significantly different: ${ }^{\mathrm{a}, \mathrm{b}} P=0.01,{ }^{\mathrm{c}, \mathrm{d}} P=0.02$ ${ }_{\mathrm{e}, \mathrm{f}} \mathrm{P}=0.03,{ }^{\mathrm{g}, \mathrm{h}} P=0.0001$

* For details of procedures, see p. 108. differences that are difficult to control for between women who have been through the maternal experience compared with nulliparous women. There is also the lack of information on pre-pregnant body weight, as there were no systematic records of weight and height that could be referred to. The comparison of the adiposity changes in women of reproductive age was performed in a sample recruited from a population who use the medical and educational services of the University of Brasilia and facilities of the nearby region. Hence, the data reported in the present study cannot be said to be a true representation of the mean change in adiposity in women of reproductive age living in the Brasilia area. In this case, the interpretation of the results can be used only to identify possible associations between weight change and the maternal experience, and should be extrapolated with caution. The present work is important in the context of Brazilian women, for whom there is very limited information regarding the maternal experience and adiposity changes, and it is only recently it has started to be investigated.

The results obtained appear to indicate that the first pregnancy is an important factor in determining changes in the distribution of adiposity. Other studies have also shown a change in body fat distribution measured by WHR (Tankelaar et al. 1990; Smith et al. 1994) or triceps:subscapular skinfold thickness (Ness, 1995) in different racial groups, including black and white Americans (Smith et al. 1994), Hispanic women living in the USA (Ness, 1995), Dutch women (Tankelaar et al. 1990) and Swedish women (Björkelund et al. 1996). The majority of the Brazilian population has a mixed racial background, which makes classification of race difficult. For the sample studied, race was classified as predominantly black or white, although for fifteen women race predominance could not be exactly defined (nine multiparous and six primiparous). In a previous analysis (results not shown) race was considered as one of the covariates, but was not significant for any of the variables studied (BMI $P=0 \cdot 13$, PBF $P=0 \cdot 15$, WHR $P=0 \cdot 36$ ), and was therefore removed from the analysis. WHR was also associated with age and smoking, with higher WHR among smoking women. The increase in central fat distribution associated with smoking has been described previously in male subjects (Seidell et al. 1991). 
The results obtained in the present study show that BMI was significantly higher $(P=0.01)$ in multiparous women. It has recently been shown that there is a mean weight gain of $0.9 \mathrm{~kg} /$ year after the first pregnancy in Brazilian women (Coitinho, 1998). In the extensive review published by Harris \& Ellison (1997) on the causes of weight gain in women who have completed at least one pregnancy, they show an average gain of $0.9-3.3 \mathrm{~kg}$ following pregnancy when compared with non-pregnant controls, and this gain persists after control for a number of socio-behavioural confounders. Certainly, it is difficult to isolate parity from other behavioural factors associated with maternity in women. Populational studies on weight trends that have controlled for parity have shown a positive association between weight gain and parity (Smith et al. 1994; Wolfe et al. 1997).

Data on the estimation of PBF from skinfold thickness values in primi- and multiparous women are scarce in the literature. Sohlström \& Forsum (1997) have measured a small $(2.5 \%)$ decrease in PBF after 12 months post-partum in a sample of eleven women followed from before pregnancy. Brewer et al. (1989) have measured large decreases in total fat content in mothers of lower parity only during the first 3 months post-partum. In our sample, nulli- and primiparous women did not significantly differ in PBF, but multiparous women presented a significant increase in PBF after age, socio-economic status and EI level were controlled for. The observed association between PBF and WHR with age in the statistical model stresses the need to control for this variable, as PBF and WHR are known to increase with age (Forbes, 1994). Hence, the measured increases in PBF and WHR with increased parity were significant (Table 2) after age was controlled for in the analysis of covariance.

The macronutrient intakes of women enrolled in the present study (Table 1), with fat $>35 \%$ total energy and carbohydrate $\leq 50 \%$ total energy, depict what has been termed a nutrition transition (Popkin, 1994; Drewnowski \& Popkin, 1997), with decreasing intakes of complex carbohydrate and fibre and increasing intakes of total fat, saturated fat and sugar. The increase in fat in the diet has been associated with an increase in obesity worldwide (Weststrate, 1995; Golay \& Bobbioni, 1997; Bray \& Popkin, 1998). We have measured the intake of cooking oil, which may contribute to the increase in the energy density of diets. The increase in energy density has been claimed as an important factor affecting weight control and obesity (Poppitt, 1995; Poppitt \& Prentice, 1996; Bell et al. 1998; Drewnowski, 1998). In the regression analysis the higher cooking oil intake for primi- and multiparous women did not reach statistical significance, presenting a smaller impact in the model comparison. However, the contribution of the increase in vegetable oils in the diet, although not significant in a cross-sectional type of study, might have adverse effects if it is a long-lasting and persistent dietary behaviour. We are not aware of any other work which has estimated cooking oil consumption among primi- and multiparous women.

Estimation of total energy through recall procedures has been shown to be a source of bias towards underestimation of dietary intake, especially for overweight women (Lichtman et al. 1992). The problems faced in the assessment of dietary intake are important and considered to be one of the fundamental obstacles preventing the collection of accurate habitual dietary intake data (Macdiarmid \& Blundell, 1998). We have observed underestimation of EI among women of higher BMI and PBF. This finding might reflect a tendency for overweight women to record less than the actual food intake, the frequent presence of cycling behaviour of lower food consumption in an attempt to reduce being overweight, and other socially-related pressures which favour underreporting of food intake (Macdiarmid \& Blundell, 1998). A similar behavioural pattern, i.e. lower measured EI for overweight women, was reported in a longitudinal study conducted to analyse determinants of weight gain and overweight in adult Finns (Rissanen et al. 1991). The tendency to under-report in the present study was independent of the parity group, since the mean EI:BMR estimated $_{\text {was }}$ 1.22 (SE 0.42), 1.38 (SE 0.53) and 1.50 (SE 0.53) for nulli-, primi- and multiparous women respectively. A value of $1.55 \times \mathrm{BMR}$ is used as the energy requirement for a sedentary lifestyle and $1.35 \times \mathrm{BMR}$ is the lowest value given for habitual energy intake of an individual compatible with a normal (not bed-bound) lifestyle (Black et al. 1991).

Physical activity levels were not associated with adiposity change in the statistical analysis. Sedentary behaviour was predominant in all groups, a pattern associated with urbanisation and modern society (Prentice \& Jebb, 1995). For primi- and multiparous women there are additional changes in lifestyle due to maternity commitments which have been shown to favour inactivity and weight retention (Rössner, 1992; Harris \& Ellison, 1997).

For the group studied, lactation did not protect primiand multiparous women from adiposity change. The mean lactation score was similar and high for primi- and multiparous women, showing that women lactated for an average of 7.5 months. In fact a number of other studies have also recognised that lactation may not protect urban women from weight gain and may even promote weight increase (Rookus et al. 1987; Dugdale \& Eaton-Evans, 1989; Dorea, 1997; AbuSabha \& Greene, 1998) and abdominal cell size increase (Björkelund et al. 1996), a result consistent with the measured increase in WHR. Physiologically, lactation is a period of increased nutritional requirement for milk synthesis and secretion (Food and Agriculture Organization/World Health Organization/ United Nations University, 1985). In general, it is considered that exclusive and persistent lactation may promote fat mobilisation and weight loss if it extends for a period of more than 3 months (Brewer et al. 1989; Öhlin \& Rössner, 1990; Dewey et al. 1993). However, the fatmobilising effect of lactation may be overcome by an increase in energy intake or energy density and the reduced level of physical activity observed in urban women. This possibility requires further investigation.

In conclusion, our results appear to indicate that the maternal experience is associated with an increase in total body weight, body fat and central accumulation of body fat in this sample of urban Brazilian women. Although these increases were below the health-risk cut-off points, the results show that primi- and multiparous women are at increased risk of becoming obese. Women undergoing the 
maternal experience (gestation and lactation) should receive advice from health professionals in order to prevent initiation of obesity. We suggest that close attention be paid to the lactation period, when appropriate nutritional and physical activity counselling should be given which favours return to the prepregnancy weight.

\section{Acknowledgements}

The authors thank Dr José G. Dorea for helpful discussion, Dr Édina S. Miasaki for performing the statistical analysis, Mr Pedro H. H. Da Costa and Steven Garcia for editorial assistance and Ms Alessandra S. Torres for help in data collection. This work was supported by a grant from Fundação de Apoio à Pesquisa do Distrito Federal (FAPDF), grant no. 193378/95-0767 and CNPq (Conselho Nacional de Desenvolvimento Científico e Tecnológico) with an undergraduate student scholarship to A. S. T.

\section{References}

AbuSabha R \& Greene G (1998) Body weight, body composition, and energy intake changes in breastfeeding mothers. Journal of Human Lactation 14, 119-124.

Bell EA, Castellanos VH, Pelkman CL, Thorwart ML \& Rolls BJ (1998) Energy density of foods affects energy intake in normalweight women. American Journal of Clinical Nutrition 67, 412-420.

Björkelund C, Lissner L, Andersson S, Lapidus L \& Bengtsson C (1996) Reproductive history in relation to relative weight and fat distribution. International Journal of Obesity 20, 213-219.

Black AE, Goldberg GR, Jebb AS, Livingstone MBE, Cole TJ \& Prentice AM (1991) Critical evaluation of energy intake data using fundamental principles of energy physiology. 2. Evaluating the results of published surveys. European Journal of Clinical Nutrition 45, 583-599.

Bradley PJ (1985) Conditions recalled to have been associated with weight gain in adulthood. Appetite 6, 235-241.

Bray GA \& Popkin BM (1998) Dietary fat intake does affect obesity! American Journal of Clinical Nutrition 68, 1157 1173.

Brewer MM, Bates MR \& Vannoy LP (1989) Postpartum changes in maternal weight and body fat depots in lactating vs nonlactating women. American Journal of Clinical Nutrition 49, 259-265.

Coitinho DC (1998) A influência da história reprodutiva no índice de mass corporal de mulheres brasileiras (The influence of reproductive history on the body mass index of Brazilian women). PhD Thesis, University of São Paulo, Brazil.

Da Costa THM \& Rodrigues MLCF (2000) Maternal experience associated with changes in body mass index and distribution of body adiposity. Proceedings of the Nutrition Society 59, 127A.

Dewey KG, Heinig MJ \& Nommsen LA (1993) Maternal weightloss patterns during prolonged lactation. American Journal of Clinical Nutrition 58, 162-166.

Dorea JG (1997) Changes in body weight and adiposity during lactation. Nutrition Research 17, 379-389.

Drewnowski A (1998) Energy density, palatability and satiety: implications for weight control. Nutrition Reviews 56, 347353.

Drewnowski A \& Popkin BM (1997) The nutrition transition: new trends in the global diet. Nutrition Reviews 55, 31-43.

Dugdale AE \& Eaton-Evans J (1989) The effect of lactation and other factors on postpartum changes in body weight and triceps skinfold thickness. British Journal of Nutrition 61, 149-153.

Durnin JVGA \& Womersley J (1974) Body fat assessed from total body density and its estimation from skinfold thickness. Measurements on 481 men and women aged from 16 to 72 years. British Journal of Nutrition 32, 77-97.

Food and Agriculture Organization/World Health Organization/ United Nations University (1985) Energy and Protein Requirements. WHO Technical Report Series, no. 724. Geneva: WHO.

Forbes GB (1994) Body composition: influence of nutrition, disease, growth and aging. In Modern Nutrition in Health and Disease, 8th ed., pp. 781-801 [ME Shils, JA Olson and M Shike, editors]. Philadelphia: Lea \& Febiger.

Garrow JS (1981) Treat Obesity Seriously. A Clinical Manual. Edinburgh: Churchill-Livingstone.

Golay A \& Bobbioni E (1997) The role of dietary fat in obesity. International Journal of Obesity 21, Suppl. 3, S2-S11.

Harris HE \& Ellison GTH (1997) Do the changes in energy balance that occur during pregnancy predispose parous women to obesity? Nutrition Research Review 10, 57-81.

Harris HE, Ellison GTH \& Holliday M (1997a) Is there an independent association between parity and maternal weight gain? Annals of Human Biology 24, 507-519.

Harris HE, Ellison GTH, Holliday M \& Lucassen E (1997b) The impact of pregnancy on the long-term weight gain of primiparous women in England. International Journal of Obesity 21, 747-755.

Heitmann BL, Lissner L, Sørensen TIA \& Bengtsson C (1995) Dietary fat intake and weight gain in women genetically predisposed for obesity. American Journal of Clinical Nutrition 61, 1213-1217.

Huang Z, Willett WC, Manson JE, Rosner B, Stampter MJ, Speizer FE \& Colditz GA (1998) Body weight, weight change, and risk for hypertension in women. Annals of Internal Medicine 128, 81-88.

Jelliffe DB (1966) The Assessment of the Nutritional Status of the Community. Geneva: WHO.

Keys A, Fidanza F, Karvonen MJ, Kimura N \& Taylor HL (1972) Indices of relative weight and obesity. Journal Chronic Diseases 25, 329-343.

Lapidus L, Bergtsson C, Larsson B, Pennert K, Rybo E \& Sjöstrom L (1984) Distribution of adipose tissue and risk of cardiovascular disease and death: a 12 year follow up of participants in the population study of women in Gothenburg. British Medical Journal 289, 1257-1261.

Lean MEJ, Sutherland HW \& Garthwaite P (1989) Obesity and fat distribution. In Carbohydrate Metabolism in Pregnancy and the Newborn, vol. 4 [HW Sutherland, JM Stowers and DWM Pearson, editors]. London: Springer-Verlag.

Lichtman SW, Pisarska K, Berman ER, Pestone M, Dowling H, Offenbacher E, Weisel H, Heshka S, Matthews DE \& Heymsfield SB (1992) Discrepancy between self-reported and actual caloric intake and exercise in obese subjects. New England Journal of Medicine 327, 1893-1898.

Macdiarmid J \& Blundell J (1998) Assessing dietary intake: who, what and why of under-reporting. Nutrition Research Reviews 11, 231-253.

Manson JE, Colditz GA, Stampfer MJ, Willett WC, Rosner B, Monson RR, Speizer FE \& Hennekens CH (1990) A prospective study of obesity and risk of coronary heart disease in women. New England Journal of Medicine 322, 882-889.

Manson JE, Willett WC, Stampfer MJ, Colditz GA, Hunter DJ, Hankinson SE, Hennekens CH \& Speizer FD (1993) Body weight and mortality among women. New England Journal of Medicine 333, 677-685.

Martins JM, Carreiras F, Falcão J, Afonso A \& da Costa JC (1998) Dyslipidaemia in female overweight and obese patients. 
Relation to anthropometric and endocrine factors. International Journal of Obesity 22, 164-170.

Monteiro CA, Mondini L, Souza ALM \& Popkin BM (1995) The nutrition transition in Brazil. European Journal of Clinical Nutrition 49, 105-113.

Mullins A (1960) Overweight in pregnancy. Lancet i, 146-147.

Ness RB (1995) Parity, adiposity and body fat distribution among Hispanic women. American Journal of Human Biology 7, 657663.

Öhlin A \& Rössner S (1990) Maternal body weight development after pregnancy. International Journal of Obesity 14, 159-173.

Öhlin A \& Rössner S (1994) Trends in eating patterns, physical activity and socio-demographic factors in relation to postpartum body weight development. British Journal of Nutrition 71, 457-470.

Öhlin A \& Rössner S (1996) Factors related to body weight changes during and after pregnancy: The Stockholm pregnancy and weight development study. Obesity Research 3, 271-276.

Popkin BM (1994) The nutrition transition in low-income countries: an emerging crisis. Nutrition Reviews 52, 285-298.

Poppitt SD (1995) Energy density of diets and obesity. International Journal of Obesity 19, Suppl. 5, S20-S26.

Poppitt SD \& Prentice AM (1996) Energy density and its role in the control of food intake: evidence from metabolic and community studies. Appetite 26, 153-174.

Prentice AM \& Jebb AS (1995) Obesity in Britain: gluttony or sloth? British Medical Journal 311, 437-439.

Rissanen AM, Heliövaara M, Knet P, Reunanen A \& Aromaa A (1991) Determinants of weight gain and overweight in adult Finns. European Journal of Clinical Nutrition 45, 419-430.

Rookus MA, Rokebrand P, Burema J \& Deurenberg P (1987) The effect of pregnancy on the body mass index 9 months postpartum in 49 women. International Journal of Obesity 11, 609-618.

Rössner S (1992) Pregnancy, weight cycling and weight gain in obesity. International Journal of Obesity 16, 145-147.

Rössner S \& Öhlin A (1995) Pregnancy as a risk factor for obesity: lessons from the Stockholm Pregnancy and Weight Development Study. Obesity Research 3, Suppl. 2, 267s-275s.

Sawaya AL, Tucker K, Tsay R, Willett W, Saltzman E, Dallal GE \& Roberts SB (1996) Evaluation of four methods for determining energy intake in young and older women: comparison with doubly labelled water measurements of total energy expenditure. American Journal of Clinical Nutrition $\mathbf{6 3}$, 491-499.

Seidell JC, Cigolini M, Deslypere J-P, Charzewska J, Ellsinger BM \& Cruz A (1991) Body fat distribution in relation to physical activity and smoking habits in 38-year-old European men. American Journal of Epidemiology 133, 257-265.

Sheldon JH (1949) Maternal obesity. Lancet ii, 869-873.

Sichieri R \& Everhart JE (1998) Validity of a Brazilian food frequency questionnaire: against dietary recalls and estimated energy intake. Nutrition Research 18, 1649-1659.

Siri WE (1961) Body composition from fluid spaces and density: analysis of methods. In Techniques for Measuring Body Composition, pp. 223-224 [J Brozek and A Henschel, editors]. Washington, DC: National Academy of Sciences.

Smith DE, Lewis CE, Caveny JL, Perkins LL, Burke GL \& Bild DE (1994) Longitudinal changes in adiposity associated with pregnancy. The CARDIA study. Journal of the American Medical Aassociation 271, 1747-1751.

Sohlström A \& Forsum E (1995) Changes in adipose tissue volume and distribution during reproduction in Swedish women as assessed by magnetic resonance imaging. American Journal of Clinical Nutrition 61, 287-295.

Sohlström A \& Forsum E (1997) Changes in body fat during the human reproductive cycle as assessed by magnetic resonance imaging, body water dilution, and skinfold thickness: a comparison of methods. American Journal of Clinical Nutrition 66, 1315-1322.

Tankelaar ID, Seidell JC, van Noord PAH, Baanders-van Halewijn EA \& Ouwehand IJ (1990) Fat distribution in relation to age, degree of obesity, smoking habits, parity and estrogen use: a cross-sectional study in 11,825 Dutch women participating in the Dam-project. International Journal of Obesity 14, 753-761.

Weststrate JA (1995) Fat and obesity. International Journal of Obesity 19, Suppl. 5, S38-S43.

Wolfe WS, Sobal J, Olson CM \& Frangillo EA (1997) Parityassociated body weight: modification by socio-demographic and behavioural factors. Obesity Research 5, 131-141.

World Health Organization (1998) Obesity: Preventing and Managing the Global Epidemic. Report of a WHO Consultation on Obesity. Geneva: WHO. 